\title{
RINK HOCKEY TEAM PERFORMANCE AND TECHNICAL DETERMINANTS OF THE GAME: A FULL-SEASON ANALYSIS
}

original paper

() Wroclaw University of Health and Sport Sciences

DOI: https://doi.org/10.5114/hm.2021.106169

\author{
MIGUEL CAMÕES ${ }^{1,2}$, RUI SILVA ${ }^{1,2}$, DIOGO OLIVEIRA ${ }^{1,2}$, TIAGO SOUSA ${ }^{3}$, \\ PEDRO BEZERRA ${ }^{1,2}$, RICARDO LIMA ${ }^{1,2}$, FILIPE MANUEL CLEMENTE $^{1,2,4}$ \\ ${ }^{1}$ Escola Superior de Desporto e Lazer, Instituto Politécnico de Viana do Castelo, Melgaço, Portugal \\ ${ }^{2}$ Research Center in Sports Performance, Recreation, Innovation and Technology, Polytechnic Institute of Viana \\ do Castelo, Viana do Castelo, Portugal \\ ${ }^{3}$ Research Unit for Sport and Physical Activity, Faculty of Sport Sciences and Physical Education, University of Coimbra, \\ Coimbra, Portugal \\ ${ }^{4}$ Instituto de Telecomunicações, Delegação da Covilhã, Covilhã, Portugal
}

\begin{abstract}
Purpose. This study aimed to analyse the correlations between individual technical determinants and the overall team performance in rink hockey sport.

Methods. Retrospective observational data were collected from 182 matches played by 14 teams competing at the first division of the Portuguese national senior rink hockey championship (full season, 2018/19). Goals scored, goals conceded, direct free-hits, penalties, and final classifications were collected by team, on the basis of the official scoresheets of the games, validated by the official referees.

Results. The results revealed that direct free-hits were more prevalent, although teams were more effective on penalties (40.4\%) than direct free-hits (27.1\%). Strong inverse relationships between direct free-hits effectiveness and final classification in the league $(r=-0.71, p=0.004)$ as well as penalties $(r=-0.58, p=0.029)$ were found. The effectiveness of the technical determinants, penalties, and direct free-hits increased with the proficiency of the teams in the classification. However, the bottom teams experienced significantly higher weights of these technical determinants on the team's total goals scored $\left(1^{\text {st }}-4^{\text {th }}: 15.3 \%, 5^{\text {th }}-9^{\text {th }}: 25.6 \%, 10^{\text {th }}-14^{\text {th }}: 23.9 \% ; p<0.05\right)$.

Conclusions. In conclusion, individual technical determinants' effectiveness was a strong predictor of team performance, accounting for at least $22.1 \%$ of the total goals scored in the full season, highlighting athletes' specialization in the training process.
\end{abstract}

Key words: rink hockey, match analysis, direct free-hits, penalties, effectiveness, technical performance

\section{Introduction}

Team sports practitioners have been progressing their knowledge in relation to the individual and technical determinants needed to outperform their opponents by observing and analysing the training- and match-related physical, technical, and tactical demands, which has led to the development of match analysis systems to collect and gather data from various sports [1]. In an environment of extreme competitivity, these data analyses could be crucial for determining and identifying training and match weakness and strengths (at both the individual and team levels) that must be improved during the training process [2].

Despite the lack of research regarding rink hockey, efforts have been made to understand the demands of this team sport. Such efforts have demonstrated a common pattern of typical intermittent demands [3], where it is expected that players have to deal with performance stressors such as sprints with high accelerations and decelerations and changes of direction, resulting in its high-intensity nature, as it has been well-documented in other team sports, such as soccer, handball, basketball, and futsal [4-8].

Correspondence address: Miguel Camões, Escola Superior de Desporto e Lazer - IPVC Complexo Desportivo e de Lazer Comendador Rui Solheiro, Monte de Prado, 4960-320 Melgaço, Portugal, e-mail: joaocamoes@esdl.ipvc.pt

Received: July 23, 2020

Accepted for publication: January 20, 2021

Citation: Camões M, Silva R, Oliveira D, Sousa T, Bezerra P, Lima R, Clemente FM. Rink hockey team performance and technical determinants of the game: a full-season analysis. Hum Mov. 2022;23(2):121-127; doi: https://doi.org/10.5114/ hm.2021.106169. 
Rink hockey, as any other team sport, is characterized by its complex dynamic system [3] in which players are expected to engage in interactions of order vs. disorder between them that may affect their behaviours throughout the game, as well as the final outcome of the match [9]. Considering the dynamic and uncertain nature of the behaviours (and for the purpose of performance analysis of this sport), the roller-hockey indoor field area has been divided into 3 corridors (left, right, and centre), 6 areas, and 18 zones [10]. Areas 1 and 2 are the defensive areas; areas 3 and 4 are the intermediate areas; and areas 5 and 6 are the definition areas, which are where the players' role actions occur during a match.

With the aim to analyse the goalkeepers' performance, Sousa et al. [10] found that the goalkeepers tended to be more effective during the first half than the second half, which might be caused by the levels of physical and mental fatigue that occurred during the match, thus decreasing goalkeeper performance determinants in the late phases of the match, as previously documented in other studies related to soccer [11]. Because of the aforementioned mental and physical fatigue - and the game-specific rules regarding faults accumulation during the second half - opportunities for direct free-hits increase as the match progresses. Further, recent research has revealed that goalkeepers are more effective in defending direct free-hits when they use the technique of moving their arms and when they assume a squatting position with a knee on the floor. Also, goalkeepers were less effective in defending direct free-hits when converted by left-handed players [12].

The team performance depends on the interaction between players on the field, supported in different moments that characterize the game: positional attack, positional defence, transitions, period of inferiority, and free shots (penalty and direct free-hit). Recent research on similar team sports (e.g., soccer, basketball, handball, futsal) has described the moments of the game when the offensive playing style of a team and offensive transitions tend to favour goal scoring for the attacking team, as well as the analysis of global performance [13-16].

Even though rink hockey is played by many athletes around the world, little is known about this sport, and the empirical knowledge of rink hockey is supported only in practice and through experience. Moreover, performing penalties and direct free-hits gives players more chances to score when compared with indirect free-hits and other moments of the game (e.g., during positional attacks and periods of inferiority), proving the importance of match analysis and previous observation. Moreover, to the best of our knowledge, specific metrics on this topic are innovative and helpful to coaches when designing training sessions.

Therefore, considering the complexity of this game, this paper analyses the correlations between team performance and individual technical determinants of rink hockey game actions. The findings may allow coaches to periodize training in accordance with the specific match demands and typical behaviour patterns of play.

\section{Material and methods}

\section{Sample}

In this study, 182 matches played by 14 teams were analysed. The teams competed in the first division of the Portuguese national hockey championship organized by the Portuguese Roller Sports Federation (Federação de Patinagem de Portugal, FPP) [17] during the 2018/19 season. As such, this cohort study includes a retrospective observational data collection for a full season.

\section{Materials and procedures}

For data collection, the FPP website was used [17], which contains all the official match details, including official spreadsheets of the games validated by the referees nominated by the FPP and available to the public. The data were subdivided into 3 parts: (1) the first round of the championship; (2) the second round of the championship; and (3) the entire championship. Data for the full 2018/19 season were collected retrospectively by 2 trained coaches of level II and III specific of rink hockey sport. As outcomes of interest, variables such as goals scored, goals conceded (and the ratio between these 2 variables), direct freehits, penalties, and final classifications were analysed. Data from each team participating in the Portuguese championship were considered. In addition, the set pieces of each team (i.e., converted and unconverted penalties in favour and against each team and converted and unconverted direct free-hits in favour and against each team) were investigated.

On the basis of the final classification of data collected from the 2018/19 season, stratification in 3 different groups was carried out in accordance with the rankings in the competitive table, which are as fol- 
Table 1. Descriptive statistics of total goals scored, penalties, and direct free-hits converted over the full season

\begin{tabular}{lccc}
\hline Descriptive data among 14 teams & Mean (SD) & Min. & Max. \\
\hline Total goals scored & $95.1(26.0)$ & 64 & 150 \\
Total penalties in favour & $20.8(4.7)$ & 15 & 29 \\
Converted penalties in favour & $8.4(2.5)$ & 4 & 14 \\
Ratio penalties converted:total goals scored (\%) & $9.2(3.3)$ & 5.6 & 18.0 \\
Total free-hits in favour & $42.8(11.2)$ & 23 & 59 \\
Converted free-hits in favour & $11.6(3.6)$ & 3 & 17 \\
Ratio free-hits converted:total goals scored (\%) & $12.9(5.2)$ & 4.0 & 21.5 \\
Ratio converted penalties and free-hits:total goals scored & $22.1(5.7)$ & 12.4 & 30.4 \\
\hline
\end{tabular}

lows: (i) champions $\left(1^{\text {st }}-4^{\text {th }}\right)$; (ii) CERS (Confédération Européenne de Roller Skating) $\left(5^{\text {th }}-9^{\text {th }}\right)$; (iii) others $\left(10^{\text {th }}-14^{\text {th }}\right)$. This stratification served to analyse the technical determinants efficacy, weight on total goals scored, and final classification of the championship.

\section{Statistical procedures}

The results were expressed as mean (standard deviation) for descriptive statistics. For efficacy calculation (\%), converted set pieces were considered divided by the total situations of a specific technical determinant (direct free-hits and penalties) or total goals of the season (weight on the total goals scored). To test the reliability between the 2 coaches, kappa coefficients (k) were calculated for the outcome variables of interest (above 0.90), indicating an almost perfect level of agreement.

The data followed normal distribution and Pearson bivariate correlations were used to analyse the relationship of the efficacy of offensive direct free-hits and penalties with the final classification in the league. As implied in the literature [18], the magnitudes of correlations were classified as trivial (0.0-0.1), small (0.1-0.3), moderate $(0.3-0.5)$, large (0.5-0.7), very large (0.7-0.9), and nearly perfect (0.9-1.0). Comparisons between technical skills efficacy, weight of these determinants on total goals scored and final classification were executed by using one-way ANOVA, with significance value of $p \leqslant 0.05$. The Bonferroni procedure was applied as a multiple comparison betweengroup post-hoc test. All statistical analyses were performed with the IBM SPSS ${ }^{\circledR}$ Statistics (version 25, Chicago, USA) for the value of $p<0.05$.

\section{Ethical approval}

The conducted research is not related to either human or animal use.

\section{Results}

As presented in Table 1, each team had an average $(S D)$ of 20.8 (4.7) penalties and 42.8 (11.2) direct free-hits on the basis of the Portuguese senior rink hockey full-season analysis. Of the offensive penalties per team, a mean $(S D)$ of 8.4 (2.5) were converted (40.3\%). In addition, even with the medium effectiveness of this technical issue on the game, the mean $(S D)$ weight of the converted penalties on total goals scored was $9.2 \%$ (3.3\%).

Regarding another technical determinant of the game, offensive direct free-hits were more prevalent: mean $(S D)$ of 42.8 (11.2) per team, full-season breakdown. Despite the higher prevalence of direct freehits, the effectiveness of this parameter was lower than that of penalties (27.1\%). In consequence, the mean $(S D)$ weight of the converted direct free-hits on total goals scored was $12.9 \%$ (5.2\%). Overall, both types of technical determinants described above had a significant weight $(22.1 \%)$ on team performance, namely on total goals scored.

When applying the Pearson bivariate correlation between the effectiveness of direct free-hits and the final classification in the rink hockey first league, a consistent inverse relationship was observed, representing a very large correlation between both $(r=$ $-0.71[-0.29 ;-0.9], p=0.004)$. The same dimensions of inverse associations were observed among penalties' effectiveness and the final classifications, representing a large correlation between both $(r=-0.58$ [ -0.07 ; $-0.85], p=0.029)$. This linear pattern is illustrated in Figure 1.

When the analysis was stratified by the proficiency level (Table 2), the teams that were in the champions' places $\left(1^{\text {st }}-4^{\text {th }}\right)$ presented greater efficacy of direct freehits and penalties, indicating means (SD) of 32.7 (2.8) and of 43.5 (3.7), respectively. In comparison, teams in CERS places $\left(5^{\text {th }}-9^{\text {th }}\right)$ had means $(S D)$ of 30.6 (6.1) 


\section{HUMAN MOVEMENT}

M. Camões et al., Rink hockey performance and technical determinants
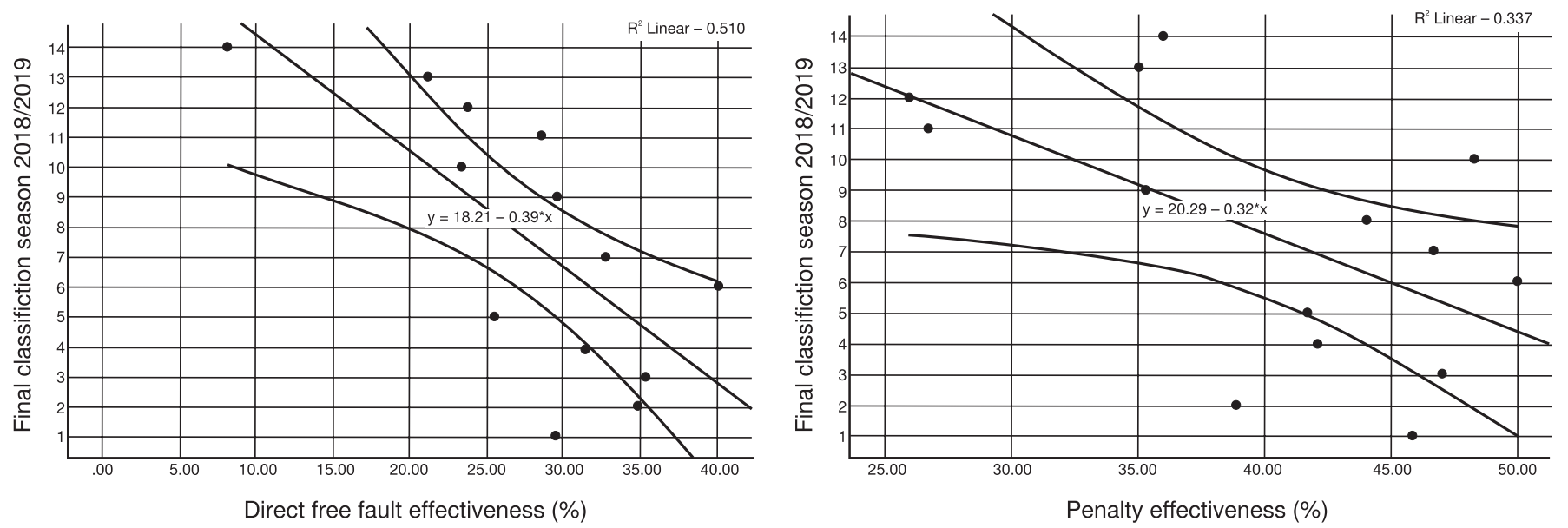

Figure 1. Relationship between the effectiveness of direct free-hits, penalties, and final classification in the championship

and 43.5 (5.6), respectively, and lower-rank teams $\left(10^{\text {th }}-14^{\text {th }}\right)$ had means $(S D)$ of $21.0(7.7)$ and $34.4(9.0)$, respectively. Despite their higher efficacy, the top 4 teams revealed significantly lower weights of converted direct free-hits and penalties on total goals scored in the league when compared with the other groups. The weights for this metric were as follows: $15.3 \%\left(1^{\text {st }}-4^{\text {th }}\right)$, $25.6 \%\left(5^{\text {th }}-9^{\text {th }}\right), 23.9 \%\left(10^{\text {th }}-14^{\text {th }}\right)(p<0.05)$.

After applying the Bonferroni procedure, in multiple comparisons, consistent significant differences were found between groups 1 and $2(p=0.006)$ and groups 1 and $3(p=0.020)$ regarding the weight of direct free-hits and penalties on total goals scored.

As mentioned above, the effectiveness of these technical determinants is an important predictor of team performance that increases the positive balance between attack and defence. A clear linear relationship was observed between the ratio of goals scored and goals conceded with the final classification in the rink hockey championship (Figure 2). This ratio explains $83 \%$ of the variation in the final classification. In addition, Figure 2 illustrates a clear gap between the 5 teams above in the table and the other teams, with the 5 best teams in the final classification all presenting ratios between attack and defence of above 0 .

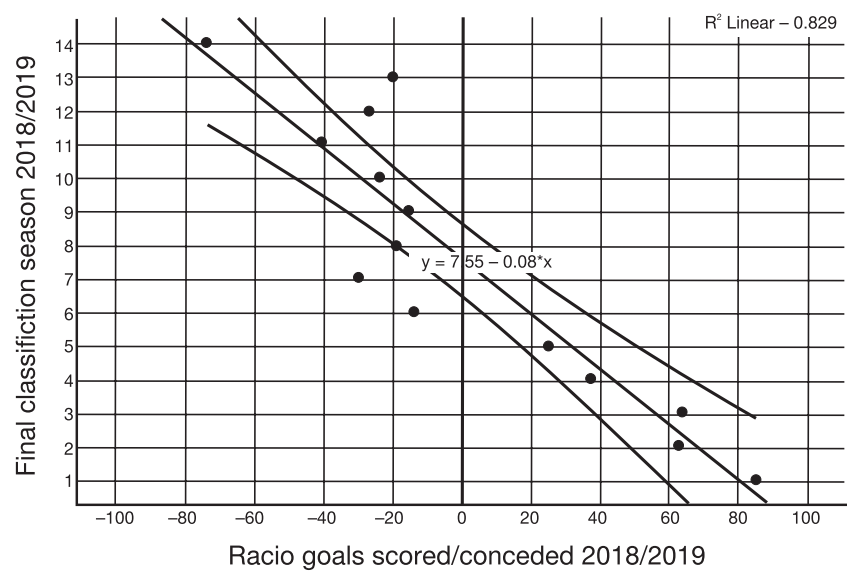

Figure 2. Relationship between the ratio of goals scored and goals conceded with final classification in the championship

\section{Discussion}

Rink hockey is characterized by consistent intermittent changes between phases/moments during the game, as is expected of any invasion sport. The different moments of a match lead to offensive actions that may result in a goal. Currently, the offensive phases or moments that characterize goals are marked by tactical complexity. The main findings of this study showed

Table 2. Technical determinants of efficacy and weight on total goals scored by category of final championship classification

\begin{tabular}{|c|c|c|c|c|}
\hline Mean $(S D)$ & Group $1^{*}$ & Group $2 * *$ & Group 3*** & $p$ \\
\hline Efficacy of direct free-hit (\%) & $32.7(2.8)$ & $30.6(6.1)$ & $21.0(7.7)$ & 0.030 \\
\hline Weight of converted direct free-hits on total goals scored (\%) & $8.8(1.5)$ & $16.0(3.8)$ & $13.1(6.4)$ & 0.106 \\
\hline Efficacy of penalties (\%) & $43.5(3.7)$ & $43.5(5.6)$ & $34.4(9.0)$ & 0.091 \\
\hline Weight of converted penalties on total goals scored (\%) & $6.5(0.8)$ & $9.6(1.6)$ & $10.8(4.7)$ & 0.137 \\
\hline $\begin{array}{l}\text { Weight of converted direct free-hits and penalties on total } \\
\text { goals scored }(\%)\end{array}$ & $15.3(2.2)$ & $25.6(3.7)$ & $23.9(4.8)$ & 0.005 \\
\hline
\end{tabular}

${ }^{*}$ champions $\left(1^{\text {st }}-4^{\text {th }}\right),{ }^{* *}$ CERS (Confédération Européenne de Roller Skating) $\left(5^{\text {th }}-9^{\text {th }}\right),{ }^{* * *}$ others $\left(10^{\text {th }}-14^{\text {th }}\right)$ 
that individual technical offensive determinants were consequences of tactical offensive actions, such as direct free-hits and penalties, and their effectiveness had a great impact on the final classification of the first league, accounting for at least $22.1 \%$ of the total goals scored. As expected, the higher classified teams exhibited higher scores of effectiveness in individual technical determinants. However, the weight of this efficacy on the total number of goals scored by each team was significantly higher on the below categories of the final classification.

Regarding the ratio of goals scored to those conceded and its linear relationship with the final classification, the top 5 teams presented a greater difference in relation to the other teams. In fact, winning teams in other team sport contexts - such as futsal [19] or handball [20] - presented greater offensive technical actions, as well as a higher ratio of goals scored to goals conceded, which resulted in better final outcomes (i.e., higher final classification) [21], which is in line with our results. This may be because the best teams generally have the best players and the best goalkeepers, as well as the best training conditions, which potentiates the balance between offensive and defensive determinants.

In rink hockey, in terms of total goals scored, direct free-hits were the most influential individual technical determinant. However, it was not as effective as total penalties in favour. These data indicate that despite being less frequent, penalties have a higher success rate in offensive terms than direct free-hits. In penalties, the goalkeepers, regarding technical issues, are more conditionate to have a global success; these are a difficult individual technical action to reproduce in training sessions. The precision and power of shots and the rule penalizing goalkeeper movements are some of the conditions that minimize exposure during training process.

Despite these differences in effectiveness, both technical determinants had an important role in the final classification. In line with the present results is a descriptive observational study of 3 games played by the Portuguese national futsal team, in which it was found that out of $56.9 \%$ of organized attacks that resulted in goals scored, $25.8 \%$ were from set pieces and only $17.4 \%$ were from counterattacks [21]. This indicates that set pieces have a great weight in the final result of a match and, therefore, in the final classification of a team. Also, in other team sport contexts (handball), it was observed that the shots from $6 \mathrm{~m}, 7 \mathrm{~m}$, and $9 \mathrm{~m}$ were the most effective offensive actions [22].
Penalties and direct free-hits are very important in rink hockey, as they are $1 \times 1$ actions, with the remaining players at a considerable distance, which often gives the player who scores the set ball a second ball (i.e., another chance to score). Moreover, the greater effectiveness in scoring from penalties than from direct freehits might be because the goalkeepers can only act from the moment the field player touches the ball. As penalties are executed closer to the goal than direct free-hits, the time that goalkeepers have to act is reduced, which may affect the final result. Also, the fact that the players start $1 \times 1$ actions (in the case of direct free-hits) gives goalkeepers the same probabilities as the field players. In addition, it makes the training process of direct free-hits more frequent, thereby improving the performance of both players involved in the technical action in contrast to the penalties exposure.

Considering the correlations of the efficacy of offensive direct free-hits and penalties with the final classification of the league, an inverse relationship was found between both situations, meaning that higher rankings depend on the effectiveness of offensive determinants. In fact, in a descriptive observational study that analysed 3 matches played by the Portuguese futsal national team in the European Selection Championship, set piece actions presented a higher rate of effectiveness (46.2\%) than organized actions (15.4\%) and counterattacks (38.5\%) [21].

Research in the handball context demonstrated a high prevalence of goals scored from 7-m hits among senior winning teams [23]. Furthermore, it was documented that winning teams had greater 7-m hit effectiveness (around 79.5\%) when compared with all other technical determinants, as well as in relation to losing teams [24]. Moreover, a clear gap was shown between winning teams and losing teams in terms of the effectiveness of offensive actions, which is in concordance with the results of the present study.

Despite these results, the top 4 teams were significantly more effective in scoring from direct free-hits and penalties than the other teams owing to the more proficient patterns of their athletes. In a study conducted during the 2013 World Handball Championship, the authors stratified teams into 3 groups by their rankings, as was done in the present study. They found that better teams had greater effectiveness in terms of total attempted shots in relation to their lower-ranked counterparts [25]. In another study that analysed performance determinants of Olympic, World, and European handball teams, it was observed that highly ranked European teams (among the top 8) had greater offen- 
sive actions efficiency than the other teams [26]. However, those offensive actions were related to offensive transitions and not set pieces. In addition, our study described that in rink hockey teams, these individual technical determinants were weighted more heavily in terms of total goals scored in low-ranked teams. This finding highlights the importance of achieving effectiveness and designing the season while preparing a specificity in the squad available.

As the effectiveness of offensive technical determinants is related to winning teams [7], it is expected that teams placed at the top of the classification depend relatively little on set pieces, as their style of play may result in better-organized attacks, transitions, and specific moments of recovering the ball, which result in goals. In contrast, other teams have significantly fewer opportunities, thus giving more weight to the individual situations that are available. Also, with regard to ball repossession and its natural offensive transition, which is typical of invasion games and of rink hockey in particular, it is more likely that a team will regain the ball in the defensive area of the field nearest to their goal [7]. Little is known about the types and direction patterns of shooting or the direct free-hit, and some studies were based on the previous rules, which placed different constraints on the actual game. However, recent research has revealed that direct free-hits in zone 3, with previous dribbling, converted by lefthanded players are the most effective [12].

The present study has some limitations. We were unable to make indirect or direct observations of the games; however, we had access to the official game bulletins provided by the FPP, validated by the official referees. All data were collected and analysed by level II and III coaches. In addition, we performed a double check of the variables of interest by trained technicians; this showed an almost perfect reliability.

On the other hand, the use of retrospective data from all teams across a full season among senior athletes provides a representative sample size of some important determinants of rink hockey. As such, this study presents some practical applications. As the efficiency of set pieces has a great influence on the final classification, the bottom teams would benefit from more exposure to set pieces during training. Observations and analyses of opponents' defensive and offensive set pieces could also help these teams to improve their effectiveness. Moreover, coaches should use players who are more comfortable converting set pieces and are highly effective in doing so, thereby promoting a cross-sectional athlete specificity.

\section{Conclusions}

This study aimed to analyse the correlations between team performance and individual technical determinants of rink-hockey actions. Top teams, specially the top 5, clearly have higher ratios of goals scored to goals conceded than low-ranked teams, which demonstrates the importance of defensive/offensive balance. While offensive direct free-hits were the most prevalent parameter, penalties were the most effective technical determinant in terms of total goals scored. Both had a direct impact (above 20\% of total goals scored) on the overall season performance - final classification. Despite the importance of the individual technical determinants, the success of the top 4 teams depended relatively little on set pieces because of their offensive style of play. Knowing what individual technical determinants are more closely related to strong team performance allows coaches to prioritize training sessions so that they can highlight their athletes' specializations.

\section{Acknowledgment}

This study was done as part of a master thesis in sports training, Escola Superior de Desporto e Lazer, Instituto Politécnico de Viana do Castelo, Portugal.

\section{Disclosure statement}

No author has any financial interest or received any financial benefit from this research.

\section{Conflict of interest}

The authors state no conflict of interest.

\section{References}

1. Taylor JB, Wright AA, Dischiavi S, Townsend MA, Marmon AR. Activity demands during multi-directional team sports: a systematic review. Sports Med. 2017;47(12): 2533-2551; doi: 10.1007/s40279-017-0772-5.

2. Gréhaigne J-F, Godbout P, Zerai Z. How the "rapport de forces" evolves in a soccer match: the dynamics of collective decisions in a complex system. Rev Psicol Deporte. 2011;20(2):747-765.

3. Yagüe PI, Del Valle ME, Egocheaga J, Linnamo V, Fernández A. The competitive demands of elite male rink hockey. Biol Sport. 2013;30(3):195-199; doi: 10.5604/ 20831862.1059211.

4. Naser N, Ali A, Macadam P. Physical and physiological demands of futsal. J Exerc Sci Fit. 2017;15(2):76-80; doi: 10.1016/j.jesf.2017.09.001.

5. Harper DJ, Carling C, Kiely J. High-intensity acceleration and deceleration demands in elite team sports competitive match play: a systematic review and meta-analy- 
sis of observational studies. Sports Med. 2019;49(12): 1923-1947; doi: 10.1007/s40279-019-01170-1.

6. Ferrari WR, Sarmento H, Vaz V. Match analysis in handball: a systematic review. Monten J Sports Sci Med. 2019;8(2):63-76; doi: 10.26773/mjssm.190909.

7. Lago-Peñas C, Lago-Ballesteros J, Rey E. Differences in performance indicators between winning and losing teams in the UEFA Champions League. J Hum Kinet. 2011;27:135-146; doi: 10.2478/v10078-011-0011-3.

8. Kniubaite A, Skarbalius A, Clemente FM, Conte D. Quantification of external and internal match loads in elite female team handball. Biol Sport. 2019;36(4):311316; doi: 10.5114/biolsport.2019.88753.

9. Gonçalves BV, Figueira BE, Maçãs V, Sampaio J. Effect of player position on movement behaviour, physical and physiological performances during an 11-a-side football game. J Sports Sci. 2014;32(2):191-199; doi: 10.1080/02640414.2013.816761.

10. Sousa T, Sarmento H, Harper LD, Valente-dos-Santos J, Vaz V. Development and validation of an observational instrument tool for analysing the activity of rink hockey goalkeepers. J Sport Pedagog Res. 2018;4(3):16-26.

11. Paul DJ, Bradley PS, Nassis GP. Factors affecting match running performance of elite soccer players: shedding some light on the complexity. Int J Sports Physiol Perform. 2015;10(4):516-519; doi: 10.1123/IJSPP.20150029.

12. Trabal G, Daza G, Riera J. Goalkeeper effectiveness in the direct free hit of rink hockey. Apunts Educ Fis Deportes. 2020;139:56-64; doi: 10.5672/apunts.2014-09 83.es.(2020/1).139.08.

13. Low B, Coutinho D, Gonçalves B, Rein R, Memmert D, Sampaio J. A systematic review of collective tactical behaviours in football using positional data. Sports Med. 2020;50(2):343-385; doi: 10.1007/s40279-01901194-7.

14. Conte D, Straigis E, Clemente FM, Gómez M-Á, Tessitore A. Performance profile and game-related statistics of FIBA 3x3 Basketball World Cup 2017. Biol Sport. 2019;36(2):149-154; doi: 10.5114/biolsport.2019.83007.

15. Méndez C, Gonçalves B, Santos J, Ribeiro JN, Travassos B. Attacking profiles of the best ranked teams from elite futsal leagues. Front Psychol. 2019;10:1370; doi: 10.3389/fpsyg.2019.01370.

16. Ferioli D, Rampinini E, Martin M, Rucco D, La Torre A, Petway A, et al. Influence of ball possession and playing position on the physical demands encountered during professional basketball games. Biol Sport. 2020;37(3): 269-276; doi: 10.5114/biolsport.2020.95638.

17. Portuguese Roller Sports Federation [in Portuguese]. Available from: https://pp.pt/.

18. Hopkins WG, Marshall SW, Batterham AM, Hanin J. Progressive statistics for studies in sports medicine and exercise science. Med Sci Sports Exerc. 2009;41(1):312; doi: 10.1249/MSS.0b013e31818cb278.

19. Balyan M, Vural F. Futsal World Cup: differences created by winning, losing and drawing variables in scored goals and offensive variations. J Educ Train Stud. 2018; 6(5):65-71; doi: 10.11114/jets.v6i5.3147.

20. Daza G, Andrés A, Tarragó R. Match statistics as predictors of team's performance in elite competitive handball. Rev Int Cienc Deporte. 2017;48(13):149-161; doi: 10.5232/ricyde2017.04805.

21. Leite WSS. Analysis of the offensive process of the Portuguese futsal team. Pamukkale J Sport Sci. 2012;3(3): 78-79.

22. Oliveira T, Gómez M, Sampaio J. Effects of game location, period, and quality of opposition in elite handball performances. Percept Mot Skills. 2012;114(3):783794; doi: 10.2466/30.06.PMS.114.3.783-794.

23. Ferrari W, Vaz V, Sousa T, Couceiro M, Dias G. Comparative analysis of the performance of the winning teams of the Handball World Championship: senior and junior levels. Int J Sports Sci. 2018;8(2):43-49; doi: 10.5923/j.sports.20180802.01.

24. Ferrari WR, dos Santos JV, Parreiral Simões Vaz V. Offensive process analysis in handball: identification of game actions that differentiate winning from losing teams. Am J Sports Sci. 2014;2(4):92-96; doi: 10.11648/ j.ajss.20140204.14.

25. Hassan A. Team Handball World Cup Championship 2013 - analysis study. J Hum Sport Exerc. 2014;9(1): 409-416; doi: 10.14198/jhse.2014.9.Proc1.26.

26. Bilge M. Game analysis of Olympic, World and European Championships in men's handball. J Hum Kinet. 2012;35(1):109-118; doi: 10.2478/v10078-012-0084-7. 